\title{
Plate fin heat sink modelling and design considerations for thermoelectric generators
}

\author{
I. T'Jollyn ${ }^{1}$, T. Pujol' ${ }^{2}$, M. De Paepe ${ }^{1}$, A. Massaguer ${ }^{2}$, L. Montoro ${ }^{2}$ \\ ${ }^{1}$ Department of Flow, Heat and Combustion Mechanics \\ Ghent University - UGent \\ Sint-Pietersnieuwstraat 41, B-9000 Ghent (Belgium) \\ Phone number: +32926432 50, e-mail: ilya.tjollyn@ugent.be, michel.depaepe@ugent.be \\ ${ }^{2}$ Department of Mechanical Engineering and Industrial Construction \\ University of Girona \\ C. de la Universitat de Girona 4, 17003 Girona (Spain) \\ E-mail: toni.pujol@udg.edu, albert.massaguer@udg.edu, lino.montoro@udg.edu
}

\begin{abstract}
This paper presents the developed model for the analysis of thermoelectric generators (TEG) with a plate fin heat sink with forced convection at the cold side. In the first part, an analytical model is created for a TEG with a constant temperature at the hot junction and a variable thermal resistance at the cold junction of the TEG. The influence of varying the thermal resistance and the electrical load on the power output and efficiency of the module is simulated. The results show that the optimal electrical load is a function of the thermal resistance. Next the influence of several design parameters of the heat sink is analyzed. The generated power by the module and the required fan power for the cooling is evaluated to achieve maximal net power output or net thermal efficiency. From these analyses several design guidelines are formulated. The net power output shows an optimal value in function of the air flow rate. Furthermore, the influence of the limits of different manufacturing techniques of plate fin heat sinks on the performance of the TEG is simulated. This shows that the theoretical optimal fin thickness and fin gap is not achievable for all industrial manufacturing techniques.
\end{abstract}

\section{Key words}

Thermoelectric generator, plate fin heat sink, thermal modelling, heat sink design

\section{Introduction}

Thermoelectric generators have received increased attention in recent years since they can be used to valorize waste heat by producing electricity, hereby contributing to the reduction of energy use. Waste heat from several sources can be utilized, such as engine exhausts [1], computer CPU's [2], municipal waste combustion [3] and many others. Many analytical models and simulation approaches for analyzing the performance of thermoelectric generators taking into account the thermal resistance have been proposed in literature. Chen et al. [4] look into the performance of a thermoelectric module with fixed thermal resistances at hot and cold junction, however he does not any for the optimal load. Gou et al. [5] validated the thermoelectric model similar to that of Chen et al. [4] with an experimental setup and found the model to be in reasonable agreement. Esarte et al. [6] analyzed the influence of flow rate, heat exchanger geometry, fluid properties and inlet temperature on the power supplied by the thermoelectric module. Only one plate fin heat sink geometry is analyzed, so no design guidelines for the heat sink parameters can be derived from this work. Chen et al. [7] performed an optimization study on the geometric parameters of a plate fin heat sink for thermoelectric generators. They analyzed the influence of the length, width of the heat sink, height and thickness of the fin, hot side temperature and external load resistance. A finite element model was used to evaluate the thermoelectric module, while the heat sink was modelled using an analytical model. The modelling however assumes that the effectiveness of the heat sink heat transfer is equal to $100 \%$, which is an assumption that will not be followed in this work.

In literature, there is no available modelling which can quickly and accurately analyze a thermoelectric module with a plate fin heat sink at the cold junction. This paper presents such a model in the next sections.

2. TEG model with varying cold junction thermal resistance

\section{A. Governing equations}

The heat transfer to the hot junction $\mathrm{Q}_{\mathrm{h}}$ and from the cold junction $\mathrm{Q}_{\mathrm{c}}$ of a thermoelectric generator can be modelled as: 


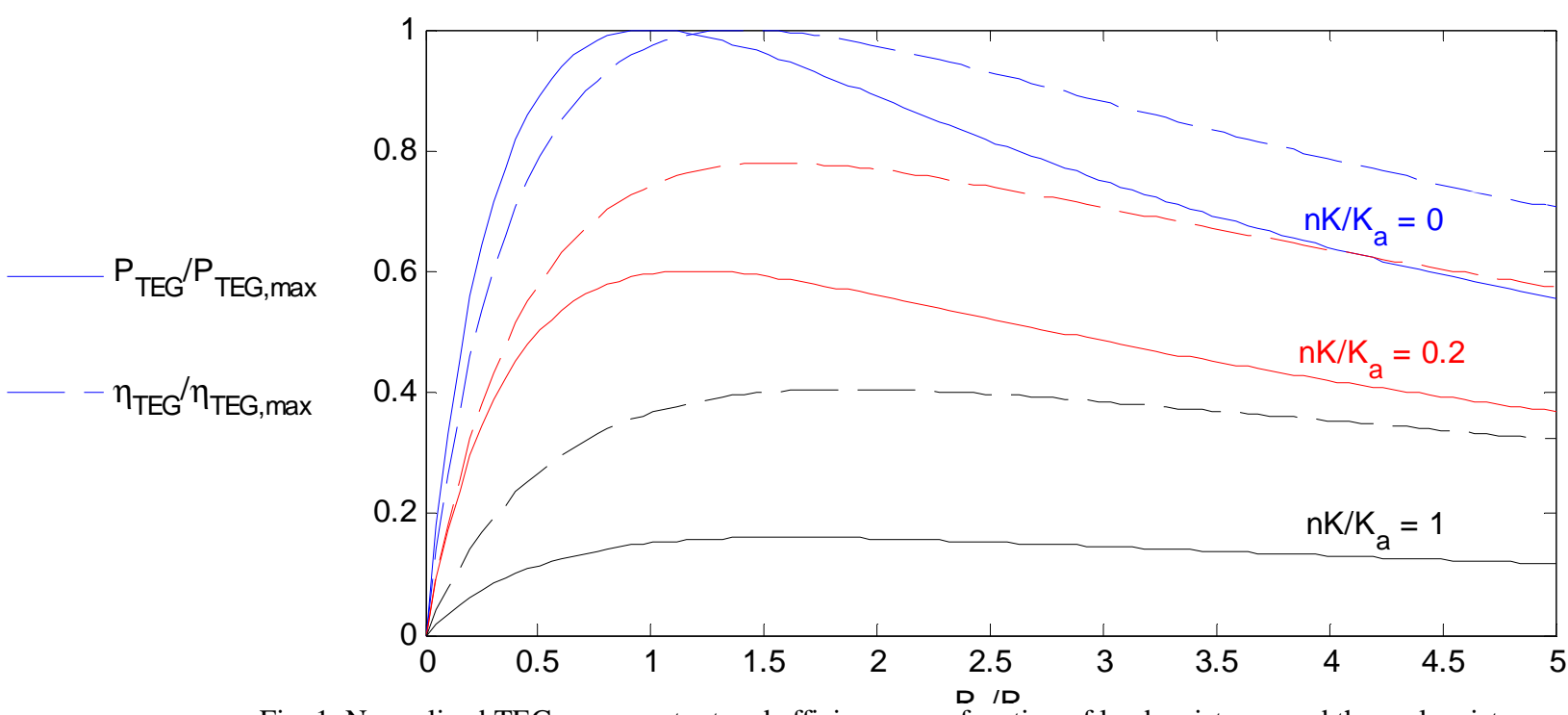

Fig. 1. Normalized TEG power output and efficiency as a function of load resistance and thermal resistance

$$
\begin{aligned}
Q_{h} & =n\left[\alpha T_{h} I-\frac{R I^{2}}{2}+K\left(T_{h}-T_{c}\right)\right] \\
Q_{c} & =n\left[\alpha T_{c} I+\frac{R I^{2}}{2}+K\left(T_{h}-T_{c}\right)\right]
\end{aligned}
$$

Where $\mathrm{n}$ is the number of thermoelectric elements, $T_{h}$ is the hot junction temperature, $\mathrm{T}_{\mathrm{c}}$ is the cold junction temperature, $\mathrm{I}$ is the current, $\mathrm{R}$ is the internal electrical resistance, $\mathrm{K}$ is the internal thermal conductance and with:

$$
\alpha=\alpha_{p}-\alpha_{n}
$$

Where $\alpha_{\mathrm{p}}$ and $\alpha_{\mathrm{n}}$ the Seebeck coefficients of the P-type and $\mathrm{N}$-type semiconductor legs. The effect of the temperature on the TEG parameters is neglected in this analysis.

The output power of the TEG $\mathrm{P}_{\mathrm{TEG}}$ equals:

$$
P_{T E G}=Q_{h}-Q_{c}=n\left[\alpha\left(T_{h}-T_{c}\right) I-R I^{2}\right]
$$

With a load resistance $\mathrm{R}_{\mathrm{L}}$, the power can also be written as:

$$
P_{T E G}=n R_{L} I^{2}
$$

The thermal efficiency of the TEG $\eta_{\text {TEG }}$ is defined as:

$$
\eta_{T E G}=\frac{P_{T E G}}{Q_{h}}
$$

The heat transfer from the cold junction can be written as a function of the conductance $\mathrm{K}_{\mathrm{a}}$ to the ambient air:

$$
Q_{c}=K_{a}\left(T_{c}-T_{a}\right)
$$

Where $T_{a}$ is the ambient air temperature.

For infinite conductance to the ambient, the cold junction temperature is equal to the ambient temperature and the power output and efficiency of the TEG are maximal. The maximum power output of the TEG is achieved when $R_{L} / R=1$ and is equal to:

$$
P_{T E G, \max }=\frac{n \alpha^{2}\left(T_{h}-T_{c}\right)^{2}}{4 R}
$$

The maximum thermal efficiency is reached when $R_{L} / R=$ $\sqrt{1+Z \bar{T}}$ and is equal to:

$$
\eta_{T E G, \max }=\left(1-\frac{T_{c}}{T_{h}}\right) \frac{\sqrt{1+Z \bar{T}}-1}{\sqrt{1+Z \bar{T}}-\frac{T_{c}}{T_{h}}}
$$

With the dimensionless figure of merit:

$$
Z \bar{T}=\frac{\alpha^{2}}{R K} \frac{T_{h}+T_{c}}{2}
$$

\section{B. Discussion modelling results}

Fig. 1 illustrates the performance of the TEG as a function of the non-dimensional load resistance $\left(\mathrm{R}_{\mathrm{L}} / \mathrm{R}\right)$ on the $\mathrm{x}$ axis and the non-dimensional thermal resistance $\left(n K / K_{a}\right)$ by different colors. The performance of the TEG is represented by the thermal efficiency (dashed lines) and the power output (full lines), both normalized with their maximal values. The graph is made for $\mathrm{T}_{\mathrm{c}} / \mathrm{T}_{\mathrm{h}}=0.5$ and $Z \bar{T}$ $=1$. Both the power output and efficiency have a maximal value as a function of the load resistance, which is given by equations (8) and (9) for the thermal resistance equal to zero. From this figure it is also clear that as the thermal conductance at the cold junction decreases, the performance of the TEG decreases. Both the power output and the efficiency still have an optimum in function of the electrical load resistance, both at different values for the load resistance. The optimal load resistance value for maximal power output or maximal efficiency is between the limit value for infinite conductance and the value $R_{L} / R=1+Z T_{h}$, which is the limit for conductance equal to zero.

The variation of the optimal load resistance in function of the thermal resistance is shown in Fig. 2. Here is illustrated the optimal non-dimensional load resistance for both maximal efficiency and maximal power output as a function of the non-dimensional thermal resistance. Also the corresponding thermal efficiency and power output are shown, normalized with their respective maximal values at thermal resistance equal to zero. The graphs are also made for $\mathrm{T}_{\mathrm{c}} / \mathrm{T}_{\mathrm{h}}=0.5$ and $Z \bar{T}=1$. It is clear from the figure that from a certain value for the thermal resistance, the power output and thermal efficiency decrease and move asymptotically to zero. 


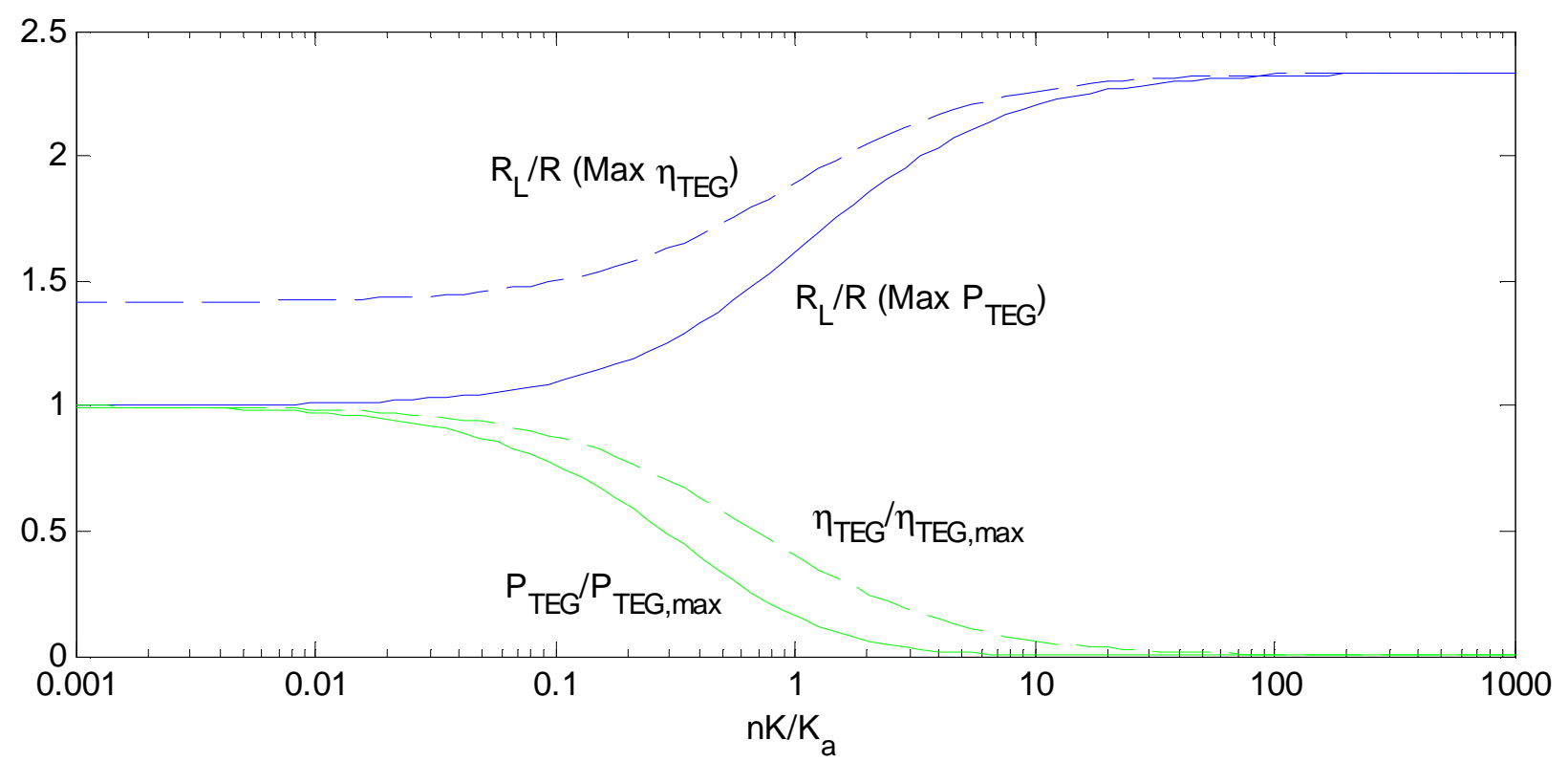

Fig. 2. Optimal load resistance and maximum TEG efficiency and power output as a function of cold junction thermal resistance

An example is calculated to show the importance of the thermal resistance. A thermoelectric module with the properties from Table I is assumed to be cooled at the cold junction by forced convection with air. Assuming a heat transfer coefficient of $200 \mathrm{~W} / \mathrm{m}^{2} \mathrm{~K}$, the thermal conductance and non-dimensional thermal resistance become:

$$
\begin{gathered}
K_{a}=200 \frac{W}{m^{2} K} 0.04 m 0.04 m=0.32 \frac{W}{K} \\
\frac{n K}{K_{a}}=1.06
\end{gathered}
$$

With the non-dimensional thermal resistance around 1 , the power output of the TEG is decreased by $82 \%$ compared to the maximal value at no thermal resistance, without taking into account the power needed for the air flow to cool the module. This short calculation shows that a lot of gains can be made with an adequately designed heat sink to reduce the cold junction thermal resistance.

\section{Plate fin heat sink modelling}

\section{A. Governing equations}

A general plate fin heat sink is shown in Fig. 3. The analytical modelling in this section is based on the work by Knight et al. [8]. When considering a constant heat flux to the air flow and $T_{c}$ equal to the average cold junction temperature, the thermal conductance can be expressed as:

$$
K_{a}=\left(\frac{2}{\rho \dot{V} c_{p}}+\frac{1}{h A_{e f f}}\right)^{-1}
$$

With $\rho$ is the air density, $\dot{V}$ the volumetric air flow, $\mathrm{c}_{\mathrm{p}}$ the air specific heat capacity, $h$ the convective heat transfer coefficient and $\mathrm{A}_{\mathrm{eff}}$ the effective heat transfer area. Here the thermal conductive resistance of the base and all thermal contact resistances are neglected, assuming they are a lot smaller than the convective thermal resistance. The effective heat transfer area is determined as:

$$
\begin{aligned}
A_{e f f} & =A_{b}+\eta_{f} A_{f} \\
A_{b} & =W L \frac{d}{d+t}
\end{aligned}
$$

$$
A_{f}=2 L H \frac{W}{d+t}
$$

Where $A_{b}$ is the base area, $\eta_{f}$ is the fin efficiency, $A_{f}$ is the fin area and $\mathrm{W}, \mathrm{L}, \mathrm{d}, \mathrm{t}$ and $\mathrm{H}$ are the geometrical parameters defined in Fig. 3. The fin efficiency is determined by:

$$
\begin{gathered}
\eta_{f}=\frac{\tanh (m H)}{m H} \\
m=\sqrt{\frac{h P_{c}}{k_{f} A_{c}}}=\sqrt{\frac{h(2 L+2 t)}{k_{f} t L}}
\end{gathered}
$$

With $\mathrm{m}$ a variable defined by equation (18), $\mathrm{P}_{\mathrm{c}}$ the perimeter of the cross section of the fin, $\mathrm{k}_{\mathrm{f}}$ the fin thermal conductivity and $\mathrm{A}_{\mathrm{c}}$ the area of the fin cross section. The assumption is made that the top of the fins are adiabatic and thus do not have convective heat transfer to the air.

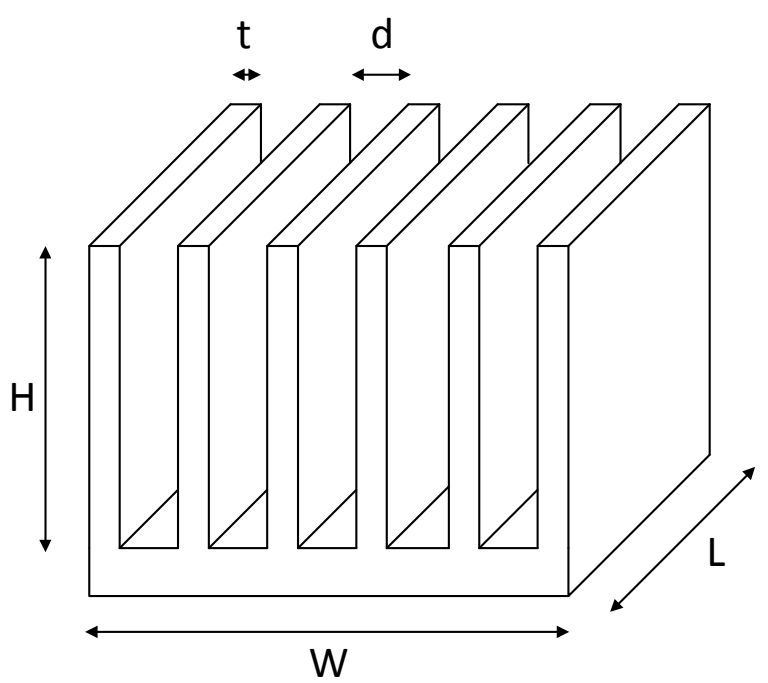

Fig. 3. Schematic of a plate fin heat sink

The convective heat transfer is calculated from the Nusselt number. The air flow is assumed to be laminar and fully developed. This is valid since the fin spacing is small, the air velocities are not very high and the length $\mathrm{L}$ is high compared to the fin spacing d. This leads to the Nusselt 
number being independent of the flow rate, but dependent on the geometry of the flow channel:

$$
\begin{gathered}
h=\frac{k N u}{D_{h}} \\
D_{h}=\frac{2 d H}{d+H} \\
N u=9.326 G-1.681 \\
G=\frac{(d / H)^{2}+1}{(d / H+1)^{2}}
\end{gathered}
$$

Where $\mathrm{k}$ is the air thermal conductivity, $\mathrm{Nu}$ is the Nusselt number, $D_{h}$ is the hydraulic diameter and $G$ is a variable dependent on de spacing to height ratio and defined by equation (22).

To provide the air flow to the heat sink, fan power is needed. The fan power $\mathrm{P}_{\text {fan }}$ can be calculated as:

$$
P_{\text {fan }}=\eta_{\text {fan }} \dot{V} \Delta p
$$

With $\eta_{\text {fan }}$ the fan efficiency and $\Delta p$ the pressure loss over the heat sink. The pressure loss is modelled as:

$$
\begin{gathered}
\Delta p=\frac{\rho v^{2}}{2} f \frac{L}{D_{h}} \\
v=\frac{\dot{V}}{H W \frac{d}{d+t}} \\
f=\frac{18.80+78.57 G}{R e} \\
R e=\frac{v D_{h}}{v}
\end{gathered}
$$

Where $\mathrm{v}$ is the average air velocity, $\mathrm{f}$ is the friction factor, Re is the Reynolds number and $v$ is the kinematic viscosity. This calculation assumes that the largest part of the pressure drop is from the flow through the channels, thereby neglecting inlet and outlet effects. This assumption is valid because the regarded fin spacing $d$ is small compared to the length $\mathrm{L}$.

The net power output $\mathrm{P}_{\text {net }}$ is calculated as the difference of the TEG power output and the fan power and the net thermal efficiency $\eta_{\text {net }}$ is calculated as the ratio of the net power output to the maximal TEG power output:

$$
\begin{gathered}
P_{\text {net }}=P_{T E G}-P_{\text {fan }} \\
\eta_{\text {net }}=\frac{P_{\text {net }}}{Q_{h}}
\end{gathered}
$$

\section{B. Simulation parameters}

The following results that are shown have been obtained for a specific thermoelectric module, TGM127-1.4-2.5. The parameters of this thermoelectric module are given in Table I and gathered from [9]. The cold junction temperature is given to be able to calculate $\mathrm{Z}$ from the figure of merit, and is a variable in the following discussions. The parameters and fluid properties in Table II are used for the heat transfer calculations.

Table I. Thermoelectric module parameters [9]

\begin{tabular}{lll}
\hline Parameter & Symbol & Value \\
\hline Number of thermocouples & $\mathrm{n}$ & 127 \\
Dimensions & $\mathrm{W}$ x L & $40 \mathrm{~mm}$ x $40 \mathrm{~mm}$ \\
Hot junction temperature & $\mathrm{T}_{\mathrm{h}}$ & $200{ }^{\circ} \mathrm{C}$ \\
Cold junction temperature & $\mathrm{T}_{\mathrm{c}}$ & $30{ }^{\circ} \mathrm{C}$ \\
\hline
\end{tabular}

\begin{tabular}{lll}
\hline Figure of merit & $Z \bar{T}$ & 0.679 \\
Seebeck coefficient & $\alpha$ & $171.981 \mu \mathrm{V} / \mathrm{K}$ \\
Electrical resistance & $\mathrm{R}$ & $6.168 \mathrm{~m} \Omega$ \\
Thermal conductance & $\mathrm{K}$ & $2.741 \mathrm{~mW} / \mathrm{K}$ \\
\hline
\end{tabular}

Table II. Heat sink parameters and air properties

\begin{tabular}{lll}
\hline Parameter & Symbol & Value \\
\hline Ambient temperature & $\mathrm{T}_{\mathrm{a}}$ & $20^{\circ} \mathrm{C}$ \\
Thermal conductivity fin material & $\mathrm{k}_{\mathrm{f}}$ & $200 \mathrm{~W} / \mathrm{mK}$ \\
Fan efficiency & $\eta_{\mathrm{fan}}$ & 0.3 \\
Air thermal conductivity & $\mathrm{k}$ & $0.026 \mathrm{~W} / \mathrm{mK}$ \\
Air density & $\rho$ & $1.205 \mathrm{~kg} / \mathrm{m}^{3}$ \\
Air specific thermal capacity & $\mathrm{c}_{\mathrm{p}}$ & $1005 \mathrm{~J} / \mathrm{kgK}$ \\
Air kinetic viscosity & $v$ & $15.11 \mathrm{~mm}^{2} / \mathrm{s}$ \\
\hline
\end{tabular}

\section{Design parameter sensitivity study}

The influence of several parameters on the net power output and net thermal efficiency is calculated for one module. The length and width is chosen equal to that of the TEG module ( $40 \mathrm{~mm} \times 40 \mathrm{~mm}$ ). The load resistance is chosen so that either the net power output or the net thermal efficiency is maximal. The flow rate, fin height, fin spacing and fin thickness are analyzed as variables.

\section{A. Flow rate}

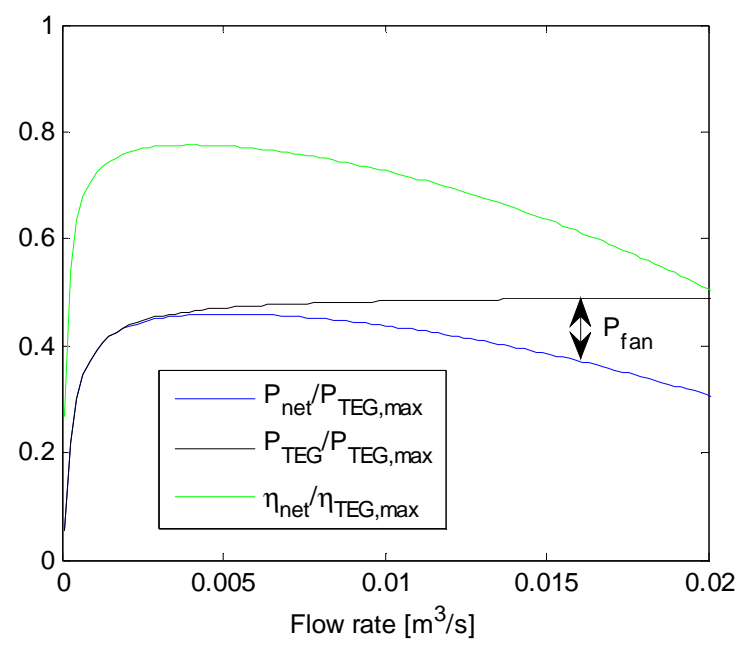

Fig. 4. Normalized net power and net thermal efficiency in function of flow rate, with $\mathrm{d}=3 \mathrm{~mm}, \mathrm{t}=1 \mathrm{~mm}, \mathrm{H}=50 \mathrm{~mm}$

The influence of the air flow rate through the plate fin heat sink on the performance of the TEG is shown in Fig. 4. The figure is made with the geometric parameters of the heat sink as follows: fin height equal to $50 \mathrm{~mm}$, fin spacing equal to $3 \mathrm{~mm}$ and fin thickness equal to $1 \mathrm{~mm}$. These are parameters that are viable for a standard extruded heat sink. The figure shows that the power output of the TEG increases with increasing flow rate. This is due to the decrease of the air outlet temperature with increasing flow rate, thereby decreasing the average cold junction temperature. This effects becomes smaller at the higher flow rates, where the convective heat transfer resistance becomes dominant. The net power output exhibits a maximum in function of the flow rate, due to the increasing fan power that is needed for higher flow rates. Both power output and efficiency exhibit a maximum value at different flow rates. The heat sink fan and flow rate should be designed at or near this maximum. The 
maximum power output is only about half of the theoretically maximal power output with no thermal resistance and no fan power. With the adaptation of the plate fin heat sink geometry, the power output can be increased.

\section{B. Fin height}

Fig. 5 illustrates the influence of the fin height on the performance of the TEG module, for fin spacing equal to 3 $\mathrm{mm}$ and fin thickness equal to $1 \mathrm{~mm}$. The load resistance and flow rate are both chosen so the power output or thermal efficiency are maximized. Both efficiency and power output are increasing with fin height. Due to the conductive thermal resistance of the fins, every increase in height reduces the fin efficiency and the effective heat transfer area increases to an asymptotic maximal value at infinite fin height. Because of this effect, the thermal resistance does not go to zero for very high fin heights, and the maximum net power output is limited to about $60 \%$ of the power output at no thermal resistance. Because of constructional and manufacturing limitations, the fin height is chosen to be $50 \mathrm{~mm}$ in the next sections.

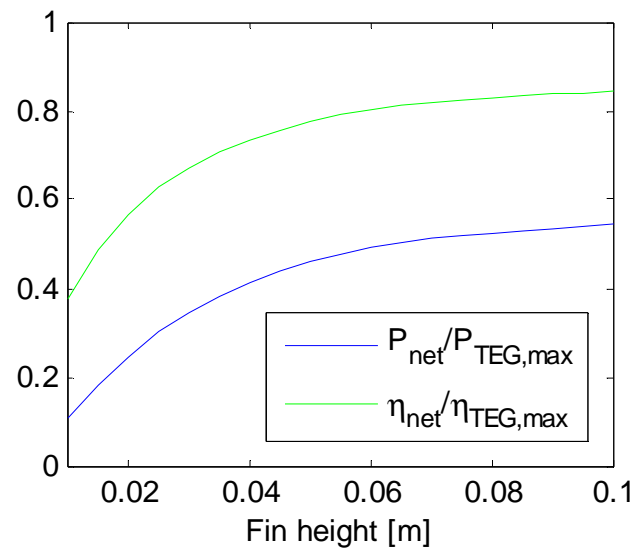

Fig. 5. Normalized net power and net thermal efficiency in function of fin height, with $\mathrm{d}=3 \mathrm{~mm}, \mathrm{t}=1 \mathrm{~mm}$

\section{Fin spacing and thickness}

Fin spacing and thickness are two parameters which interact significantly in the thermal performance of the plate fin heat sink, so they are analyzed together. Fig. 6 shows the

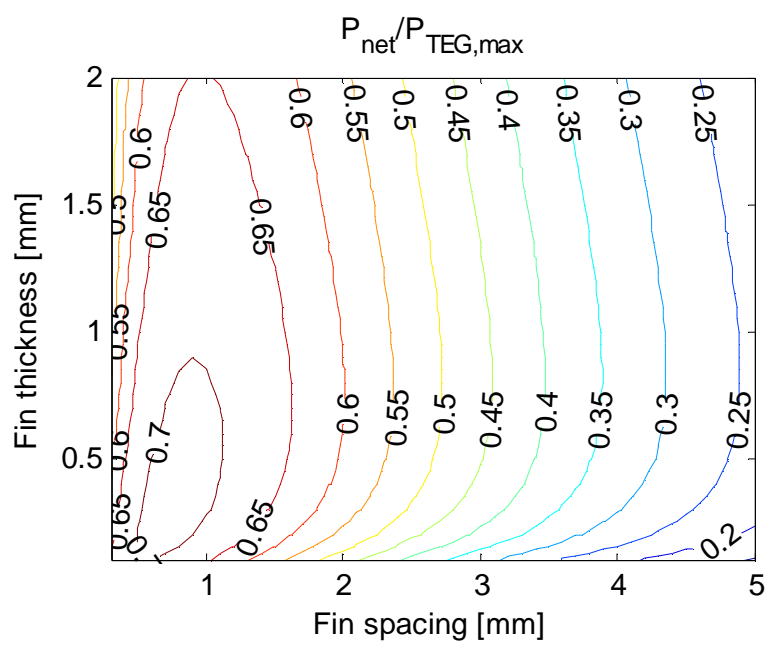

normalized net power output (left) and the normalized net thermal efficiency (right) in function of the fin spacing ( $\mathrm{x}$ axis) and the fin thickness (y-axis). In these figures both the load resistance and the flow rate have been chosen to either maximize the net power output or the net thermal efficiency. The figure indicates that the fin spacing has a larger influence on the performance than the fin thickness. The optimal fin spacing is around $0.8 \mathrm{~mm}$ and the optimal fin thickness is around $0.35 \mathrm{~mm}$ for both maximal net power output and maximal net thermal efficiency. The maximal power output is about $71 \%$ of the maximal power output with no thermal resistance and fan power.

\section{Comparison of heat sink manufacturing techniques}

The geometrical parameters are limited by manufacturing and strength constraints, which are different for different manufacturing techniques. Also the type of material that can be used is dependent on the manufacturing technique. Table III gives an overview of the limitations for four different manufacturing techniques (extrusion, bonding, folding and skiving), which were gathered from different manufacturers. The height is in each case limited to 50 $\mathrm{mm}$, which is mostly recommended for the manufacturing process and for the structural strength of the fins.

Table III. Heat sink parameters and air properties ( $\mathrm{Al}=$ aluminum, $\mathrm{Cu}=$ copper $)$

\begin{tabular}{cccc}
\hline $\begin{array}{c}\text { Manufacturing } \\
\text { technique }\end{array}$ & $\begin{array}{c}\text { Material } \\
\text { (conductivity) }\end{array}$ & $\begin{array}{c}\text { Fin } \\
\text { spacing }\end{array}$ & $\begin{array}{c}\text { Fin } \\
\text { thickness }\end{array}$ \\
\hline Extrusion & $\begin{array}{c}\mathrm{Al} \\
(200 \mathrm{~W} / \mathrm{mK})\end{array}$ & $>3 \mathrm{~mm}$ & $>1 \mathrm{~mm}$ \\
Bonding & $\begin{array}{c}\mathrm{Al} / \mathrm{Cu} \\
(200 / 385 \mathrm{~W} / \mathrm{mK})\end{array}$ & $>3 \mathrm{~mm}$ & $>0.5 \mathrm{~mm}$ \\
& $\begin{array}{c}\mathrm{Al} / \mathrm{Cu} \\
\text { Folding }\end{array}$ & $>1 \mathrm{~mm}$ & $>0.2 \mathrm{~mm}$ \\
& $\begin{array}{c}(200 / 385 \mathrm{~W} / \mathrm{mK}) \\
\mathrm{Cu}\end{array}$ & $>0.25 \mathrm{~mm}$ & $>0.15 \mathrm{~mm}$ \\
\hline
\end{tabular}

Fig. 7 illustrates the influence on the TEG performance of the heat sink geometry limitations in function of the manufacturing process. This analysis does not take into account the thermal contact resistance between the base and the fin which is introduced when using the bonding or

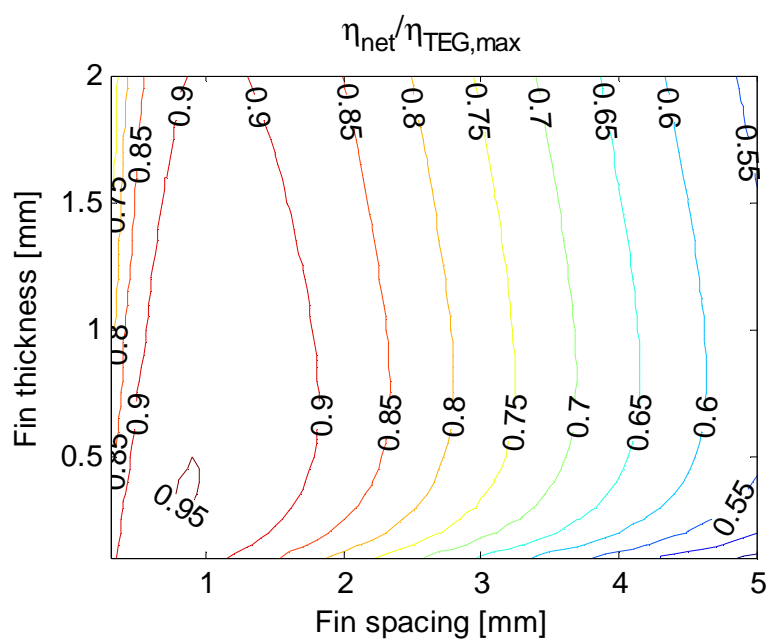

Fig. 6. Normalized net power output (left) and net thermal efficiency (right) in function of fin spacing and thickness, with $\mathrm{H}=50 \mathrm{~mm}$ 
folding manufacturing technique. For the same manufacturing technique, using copper instead of aluminum increases the performance slightly, due to the higher thermal conductivity of copper. Extruded and bonded aluminum heat sinks perform almost equally, since the performance is mostly limited by the fin spacing, as shown in the previous paragraph. Because the minimal limit in the fin spacing for both processes is about the same, the performance is also comparable. Folded and skived heat sinks have remarkably higher performance, due to the lower achievable fin spacing. The optimal fin spacing is around $0.8 \mathrm{~mm}$, which is a little lower than the minimal fin spacing achievable with folded heat sinks. This explains why there is a slightly higher performance predicted for the skived heat sink. The maximal achievable net power output using these configurations is $74 \%$ of the power output of the TEG with no fan power and no thermal resistance.

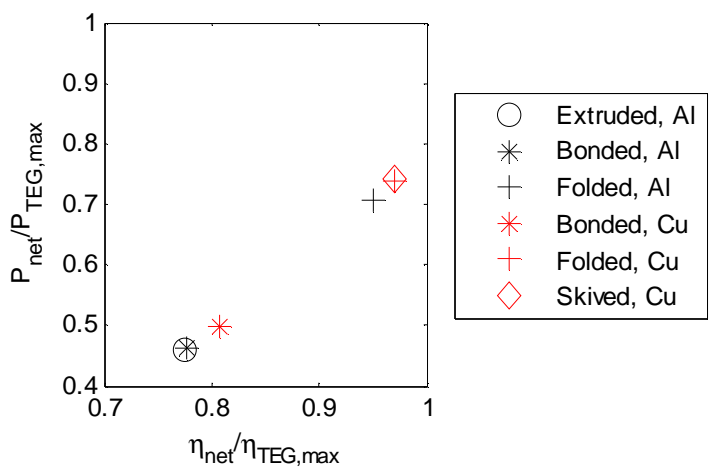

Fig. 7. Normalized net power output and net thermal efficiency for different heat sink manufacturing techniques

\section{Conclusions}

An analytical model of a thermoelectric generator (TEG) with a constant temperature at the hot junction and a variable thermal resistance at the cold side is constructed. The modelling results illustrates that taking into account the thermal resistance is necessary to obtain accurate modelling results. Adequate design of the heat sink is crucial for the performance of the TEG. Using no heat sink and forced convection, the TEG power output can be reduced to as low as $20 \%$ of the maximal possible power output. Using an optimized heat sink design with forced convection, the power output can be increased up to $74 \%$ of the maximal possible power output. It is shown that the power and thermal efficiency have a maximum value in function of the load resistance or current drawn from the TEG, which is dependent on the thermal resistance. Using the combined TEG and heat sink model, it is shown that there is an optimal flow rate to which should be designed, which balances the TEG power output and the needed fan power. Increasing the height of the heat sink increases the performance. However the performance tends to go to an asymptotic maximum, and the height chosen in practical applications is usually limited by the manufacturing process or by the structural strength of the fins. It is found that there is also an optimal value for the fin spacing and the fin thickness, which are for this case $0.8 \mathrm{~mm}$ and $0.35 \mathrm{~mm}$ respectively. From the modelling results, it is shown that skived and folded heat sinks can perform better than bonded and extruded heat sinks, since the manufacturing process of the latter two limits the minimal fin spacing. In future work, experiments will be performed on different heat sinks geometries to validate the analytical model. Future modelling efforts can also include thermal resistance at the hot junction of the TEG and thermal contact resistances. Another possibility is to assess the influence of the combination of several modules in close proximity on the thermal heat sink performance.

\section{Acknowledgement}

The authors would like to thank the Flemish Fund for Scientific Research FWO for the funding of the research exchange between the University of Ghent and the University of Girona. TP, AM and LM acknowledge the support of this work provided by the University of Girona under grant MPCUdG2016-4.

\section{References}

[1] K. M. Saqr, M. K. Mansour and M. N. Musa, "Thermal design of automobile exhaust based thermoelectric generators: Objectives and challenges," International Journal of Automotive Technology, vol. 9, nr. 2, pp. 155-160, 2008.

[2] Y. Zhou, S. Paul and S. Bhunia, "Harvesting wasted heat in a microprocessor using thermoelectric generators: modeling, analysis and measurement," in Proceedings of the conference on Design, automation and test in Europe, 2008.

[3] T. Kajikawa, "Status and future prospects on the development of thermoelectric power generation systems utilizing combustion heat from municipal solid waste," in Proceedings International Conference on Thermoelectrics, 1997.

[4] L. Chen, J. Gong, F. Sun and C. Wu, "Effect of heat transfer on the performance of thermoelectric generators," International journal of thermal sciences, vol. 41, nr. 1, pp. 95-99, 2002.

[5] X. Gou, H. Xiao and S. Yang, "Modeling, experimental study and optimization on lowtemperature waste heat thermoelectric generator system," Applied energy, vol. 87, nr. 10, pp. 31313136, 2010.

[6] J. Esarte, G. Min and D. M. Rowe, "Modelling heat exchangers for thermoelectric generators," Journal of Power Sources, vol. 93, nr. 1, pp. 72-76, 2001.

[7] W. H. Chen, S. R. Huang and Y. L. Lin, "Performance analysis and optimum operation of a thermoelectric generator by Taguchi method," Applied Energy, vol. 158, pp. 44-54, 2015.

[8] R. W. Knight, J. S. Goodling and D. J. Hall, "Optimal thermal design of forced convection heat sinks - analytical," Journal of Electronic Packaging, vol. 113, nr. 3, pp. 313-321, 1991.

[9] A. Elarusi, N. Illendula and H. Fagehi, Performance Prediction of Commercial Thermoelectric Generator Modules using the Effective Material Properties, Western Michigan University, 2014. 